\title{
Effect of the diel light cycle on the diving behaviour of two bottom feeding marine birds: the blue-eyed shag Phalacrocorax atriceps and the European shag $P$. aristotelis
}

\author{
Sarah Wanless ${ }^{1, *}$, Suzanne K. Finney ${ }^{1}$, Michael P. Harris ${ }^{1}$, Dominic J. McCafferty ${ }^{2}$ \\ ${ }^{1}$ Institute of Terrestrial Ecology, Hill of Brathens, Glassel, Banchory, Kincardineshire AB31 4BY, United Kingdom \\ ${ }^{2}$ British Antarctic Survey, Natural Environment Research Council, High Cross, Madingley Road, Cambridge CB3 0ET, \\ United Kingdom
}

\begin{abstract}
Consistent diel patterns in foraging depths have been recorded in several avian predators which feed on pelagic prey, but nothing is known about such effects in bottom feeding seabirds. In the underwater environment, illumination is influenced primarily by water depth. Thus a predator's ability to exploit feeding areas located in deep water could, theoretically, be constrained by light availability. We investigated the effects of the diel light cycle on the diving behaviour of 2 species of bottom feeding seabird: the blue-eyed shag Phalacrocorax atriceps and the European shag $P$. aristotelis. Tinebased data loggers were attached to 22 blue-eyed shags and 21 European shags and used to obtain detailed and concurrent records of foraging conditions in terms of depth and illumination during the chick-rearing period. Both species were exclusively diurnal feeders. There were marked differences in mean foraging depth and foraging illumination between individual birds (blue-eyed shag: ranges 3.2 to $73.3 \mathrm{~m}$ and -0.3 to $2.0 \log _{10} \mathrm{~lx}_{\text {; }}$ European shag: 8.5 to $34.6 \mathrm{~m}$ and 0.9 to $2.0 \log _{10} \mathrm{~lx}$ ). Superimposed on this variation was a consistent effect whereby individuals significantly modified their diving behaviour in response to the diel light cycle, in accord with the prediction that foraging depths would be maximised when ambient illumination was highest. However, it appeared that individuals did not fully exploit the potential of this diel effect since, although foraging depths in the middle of the day were generally deeper, the associated illumination was higher than that experienced during shallower dives made earlier or later in the day. Nevertheless, we believe that diel effects can play an important role in shaping the foraging behaviour of battom feeding, avian predators.
\end{abstract}

KEY WORDS: Phalacrocoracidae Phalacrocorax - Dive depth · Illumination · Vision · Foraging

\section{INTRODUCTION}

Most marine birds rely on sight to locate and capture their prey, the main exceptions being some procellariiformes which can also use smell to detect food (Campbell \& Lack 1985, Nevitt et al. 1995). This dependence on vision means that light availability is likely to be an important factor influencing the foraging behaviour of seabirds, which frequently feed on highly mobile prey such as shoaling fish. In the underwater environment, illumination is not only influenced by date and time

•E-mail: swanl@ite.ac.uk of day, but also by attenuation of light with depth throughout the water column and water turbidity. If birds are constrained by the illumination at which they can forage efficiently, we would predict that foraging depths should vary in relation to the diel light cycle, with the deepest dives occurring around midday.

Studies on penguins have demonstrated a diel pattern in depth utilisation, with birds making shallow dives at night and restricting deep dives to daylight hours (Wilson et al. 1993, Kirkwood \& Robertson 1997, Peters et al. 1998, Pütz et al. 1998). In addition, the depths at which birds foraged increased after dawn with increasing ambient light levels and decreased 
again towards dusk. These studies concluded that a primary determinant of depth utilisation was the extent to which birds could see their prey. However, in all cases the birds were feeding on prey species which themselves showed diel vertical migrations through the water column. Although the prey capture rate of penguins is lower at night, which suggests that illumination can directly limit foraging efficiency (Wilson et al. 1993), the daily pattern in foraging depth may also be influenced by diel variations in prey distribution and dispersion.

The aims of our study were to obtain the first direct measurements of the illumination experienced during foraging by 2 species of shag (Phalacrocoracidae), the blue-eyed shag Phalacrocorax atriceps and the European shag $P$. aristotelis, and to integrate these data with concurrent records of foraging depth to test the hypothesis that individuals adjusted their foraging depths in relation to the diel light cycle. The work was carried out at South Georgia (blue-eyed shag, though the population is sometimes referred to as the South Georgian shag P. georgianus [Marchant \& Higgins 1990) and southeast Scotland (European shag), sites with very similar latitudes $\left(54^{\circ} \mathrm{S}\right.$ and $56^{\circ} \mathrm{N}$ respectively). In addition, data were collected during the austral and northern summers, and thus the diel light cycles were broadly comparable.

\section{METHODS}

Study area and species. Blue-eyed and European shags are foot-propelled pursuit divers which, in both of these study areas, are thought to feed predominantly on or near the seabed. The European shag feeds on a variety of benthic and free-swimming fish, but its diet on the Isle of May, Firth of Forth, southeast Scotland, consists almost exclusively of sandeels Ammodytes marinus during the breeding season (Wanless et al. $1993 \mathrm{a}, \mathrm{b})$. The diet of the blue-eyed shag on South Georgia is much more variable, with crustaceans, polychaetes, octopuses and small nototheniid fish being the most common prey items (Wanless et al. 1992). The species differ in diving performance, with blue-eyed shags typically making longer, deeper dives than European shags (Croxall et al. 1991, Wanless et al. 1991).

Data were collected from 22 blue-eyed shags at Bird Island, South Georgia $\left(54^{\circ} 00^{\prime} \mathrm{S}, 38^{\circ} 02^{\prime} \mathrm{W}\right)$, and 21 European shags on the Isle of May $\left(56^{\circ} 11^{\prime} \mathrm{N}, 2^{\circ} 33^{\prime} \mathrm{W}\right)$. All birds were sampled during the chick-rearing period.

Diving behaviour. All birds were captured at the nest and a time-depth recorder (TDR Mk 5, Wildlife Computers, Woodinville, WA, USA) was attached to the feathers in the centre of the back, using waterproof tape and 2 cable-ties. The process of attachment took between 1 and $3 \mathrm{~min}$. The TDRs measured $6 \times 3.5 \times$ $1.5 \mathrm{~cm}$ and weighed $50 \mathrm{~g}$. Although the TDRs represented only ca $2 \%$ of the adult body mass of both species they likely increased the energy expenditure during foraging due to hydrodynamic drag (Culik \& Wilson 1991, Schmid et al. 1995). However, the aim of our study was to investigate diurnal patterns of depth utilisation in relation to light conditions and, since there was no obvious disruption to attendance behaviour of the instrumented birds, we assumed that the data collected would be representative of normal diving behaviour. Depth data were recorded at a resolution of $1 \mathrm{~m}$ and illumination on an arbitrary scale (details of calibration are provided later). Measurements were recorded each second. Most birds were recaptured after $24 \mathrm{~h}$ (all within $53 \mathrm{~h}$ ), the TDR removed and the recorded data downloaded.

Analysis of TDR data. The diving profile for each bird was reconstructed using a purpose-built software program (Boyd et al. 1997). A dive was defined as any excursion below the surface to a depth of $>2 \mathrm{~m}$. Both species typically made U-shaped, flat-bottomed dives (Fig. 1). As the conditions experienced by shags while foraging was the area of interest, rather than the period spent travelling through the water column, only data from the flat-bottomed phase of the dive cycle were used in the analyses, as this was assumed to be when prey capture occurred. Although depth was approximately constant during the bottom phase of the dive cycle, illumination showed some variation (Fig 1). The cause of this variation is unknown, but may possibly be related to changes in the position of the bird's body with respect to the sea surface as it investigates cracks and crevices, and/or individuals disturbing the sediment as they feed thereby causing local turbidity to increase dramatically. The foraging conditions for each dive were therefore estimated as the mean illumination and depth over this period. Non U-shaped dives, and dives with a bottom phase lasting less than $10 \mathrm{~s}$ were excluded from the analyses $(<5 \%$ of dives for each species).

Calibration procedure. The TDRs recorded light using a photodiode (BPX 63 Siemens Microelectronics Inc., Cupertino, USA) which had a spectral sensitivity of 350 to $1100 \mathrm{~nm}$ with a peak sensitivity at $800 \mathrm{~nm}$. The sensor was calibrated in a darkroom using a light source (Lamp 7PL70) which had been calibrated against a standard light source at the National Physical Laboratory, Teddington, UK. The TDR was placed $1 \mathrm{~m}$ from the light source, where it was exposed to 16 different illumination levels using neutral density glass filters (Ealing Electro-Optics, UK). The TDR was programmed to record illumination every second, which gave 60 readings at each light level. The mean of the 60 readings was plotted against the known illumina- 
tion and a best-fit line using least squares regression was calculated to provide a calibration equation: Illumination $\left(\log _{10} \mathrm{~lx}\right)=$ 0.046 TDR light units -4.95 (range 0 to 154 TDR light units, $\mathrm{R}^{2}=98 \%, F_{1,14}=661$, $\mathrm{p}<0.0001)$.

Analysis. We attempted to standardise the timing of data collection at the 2 study areas, but because breeding occurs later at Bird Island and logistic problems at this colony are more severe, the period over which data were collected on Bird Island was 3 times longer than on the Isle of May (43 d compared to $13 \mathrm{~d}$ ) and was after rather than centered on the summer solstice (1 January to 13 February 1995 compared to 15 June to 28 June 1996). However we believe that these differences did not affect our results because: (1) foraging data were standardised against midday not dawn or dusk (see later), (2) our unit of analysis was the individual and birds were only sampled for about $24 \mathrm{~h}$, (3) progressive changes in day length around the solstice are comparatively small, and (4) in neither species was there evidence of a systematic change in dive depth with date. Accordingly, data from the 2 study areas were standardised for diel changes in illumination by constructing average time-depth profiles for a range of different illumination categories using output from the TDRs. The time of day when light penetration was at a maximum, i.e. the lowest point on the curve, was estimated for each light category and the average value for each study area calculated. The time of the start of each dive was standardised against this , average value and expressed as minutes from the time of maximum light intensity. Thus, dives that occurred in the middle of the day had low time values while those made early or late in the day had high values. From this approach it was also apparent that, at least over the range of depths common to the 2 areas ( 1 to $40 \mathrm{~m}$ ), light attenuation due to depth was broadly similar in the waters around Bird Island and the Isle of May.

To test the hypothesis that foraging depth and illumination in the 2 species of shags were related to diel light conditions we used a General Linear Model (GLM; Minitab Inc. 1996) in which individual birds were used as a factor and the square of the minutes from the time of maximum light intensity $\left(\mathrm{TMLI}^{2}\right)$ as an explanatory variable. A quadratic term was used in the model because this provided a better description of a response to the diel light cycle than a simple linear model. The interaction between bird and $\mathrm{TMLI}^{2}$ was used to test for differences in the responses of different individuals. (a) Bluci-cyed shag

European shag
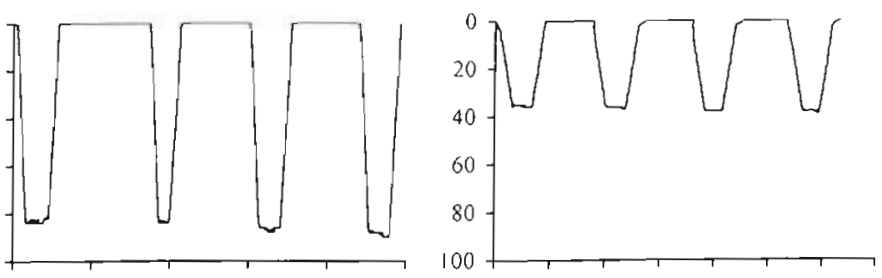

(b)
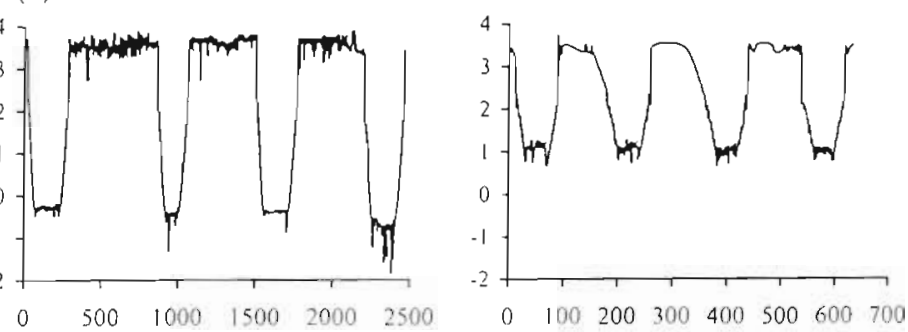

Time (seconds)

Fig. 1. Output of dive analysis programme showing examples of (a) dive pean shag. Plots illustrate the flat-bottomed dive shape typical of the majority of dives. (Note: different $x$-axis scales are used for each species)

\section{RESULTS}

Illumination and dive depth were both recorded for all 21 European shags and for 15 of the 22 blue-eyed shags; for 7 blue-eyed shags only depth was recorded. The number of dives recorded for each bird, and hence estimates of foraging depth and illumination, varied from 16 to 267 (mean $=81.4, \mathrm{SE}=15.1$ ) for blue-eyed shags, and from 11 to 151 (mean $=57.3, \mathrm{SE}=7.9)$ for European shags.

Both species were exclusively diurnal feeders with no dives recorded between $22: 50$ and $06: 10 \mathrm{~h}$ and between $21: 50$ and 05:50 h local time for blue-eyed and European shags respectively. In terms of ambient illumination these schedules indicated that, on average, blue-eyed shags and European shags refrained from foraging when illumination in the colony fell below $2.0(\mathrm{SE}=0.17)$ and $3.0(\mathrm{SE}=0.09) \log _{10} \mathrm{~lx}$ respectively.

Frequency distributions of the illuminations experienced by blue-eyed and European shags during the bottom (foraging) phase of the dive are shown in Fig. 2. The lowest illuminations utilised were -1.3 and $0.2 \log _{10}$ lx respectively.

Foraging depths of both blue-eyed shags and European shags showed highly significant bird effects $\left(F_{1,21}=302.9, \mathrm{p}<0.001\right.$, and $F_{1,20}=37.2, \mathrm{p}<0.001$, respectively). Individual mean values for blue-eyed shags ranged from 3.2 to $73.3 \mathrm{~m}$ loverall mean = $38.2 \mathrm{~m}, \mathrm{SE}=4.8, \mathrm{n}=22$ birds) and for European shags 

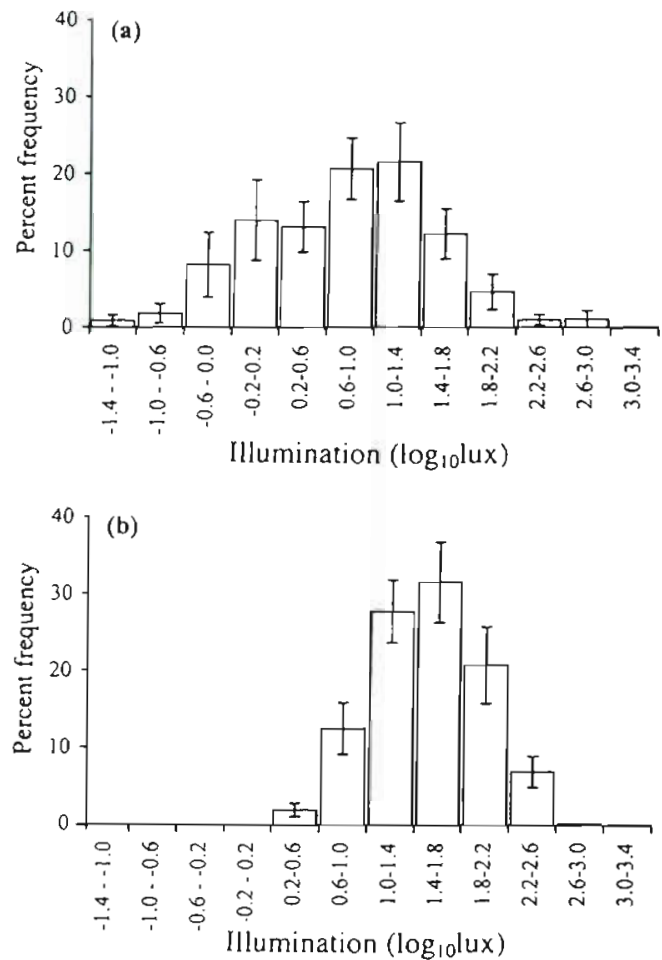

Fig. 2. Frequency $(\%)$ distributions of foraging illuminations experienced by (a) blue-eyed shags and (b) European shags. Bars represent overall means estimated from separate distributions for each individual $(n=15$ blue-eyed shags and $n=21$

European shags) and error bars indicate 1 standard error

from 8.5 to $34.6 \mathrm{~m}$ (overall mean $=20.5 \mathrm{~m}, \mathrm{SE}=1.3, \mathrm{n}=$ 21 birds). This variation was associated with significant differences in the mean foraging illumination experienced by individual blue-eyed shags $\left(F_{1,14}=115.3, p<\right.$ 0.001 ; mean $=0.7 \log _{10} \mathrm{~lx}, \mathrm{SE}=0.2$, range $=-0.3$ to $2.0 \log _{10} \mathrm{~lx}, \mathrm{n}=15$ birds $)$ and European shags $\left(F_{1,20}=\right.$ $27.1, \mathrm{p}<0.001$; mean $=1.5 \log _{10} \mathrm{~lx}, \mathrm{SE}=0.1$, range $=$ 0.9 to $2.0 \log _{10} l \mathrm{x}, \mathrm{n}=21$ birds)

Overall, mean dive depth explained $86.7 \%$ of the variation in mean foraging illumination experienced by blue-eyed shags and $71.3 \%$ in European shags (Fig. 3), with no significant difference between species in the slopes of these relationships $\left(F_{1,32}=1.66, \mathrm{p}=0.20\right)$.

Among blue-eyed shags TMLI ${ }^{2}$ had a significant and negative effect on dive depth, indicating that dives tended to be deeper around midday $\left(F_{1,21}=5.7, \mathrm{p}<0.05\right)$. However, individuals differed significantly in the strength of their response (as indicated by a significant interaction between foraging depth and $\operatorname{TMLI}^{2}\left(F_{1,21}=\right.$ $38.2, p<0.001)$. Among European shags there was no evidence that $\mathrm{TMLI}^{2}$ had a significant effect on dive depth $\left(F_{1,20}=0.002, p=0.96\right)$, but the interaction between bird and TMLI ${ }^{2}$ was significant $\left(F_{1.20}=14.3\right.$, $p<0.001$ ). a) Blue-eyed shag

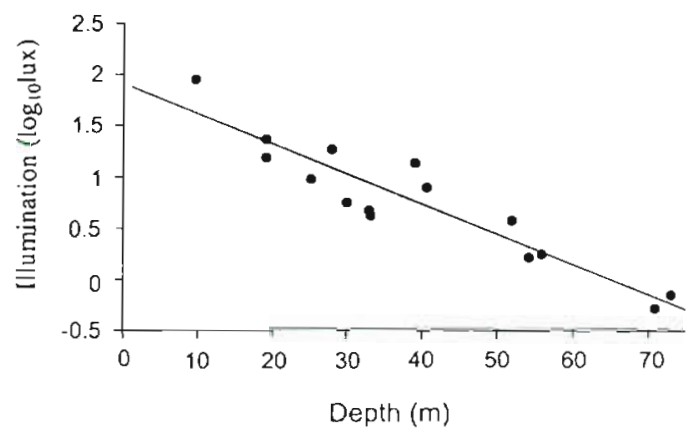

b) European shag

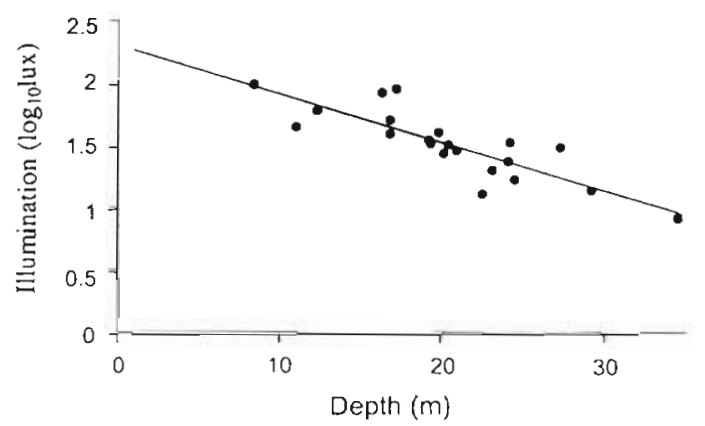

Fig. 3. Relationships between mean foraging illumination and foraging depth in individual (a) blue-eyed shags and (b) European shags. Equations for the lines are: $y=1.91-0.03 x, F_{1,13}$ $=85.0, \mathrm{p}<0.001 ;$ and $y=2.32-0.04 x, F_{1,19}=47.2, \mathrm{p}<0.001$, respectively

To explore these individual differences further we used the regression coefficient for each bird as an indication of the strength of the depth response. This variation appeared to be negatively related to diving depth (Fig. 4). However, 1 blue-eyed shag and 1 European shag did not conform to this trend. In contrast to the other birds which typically foraged within a narrow depth range, these 2 individuals showed a marked change in foraging depth during the period that they were followed, a pattern which was consistent with a major change of feeding area. Excluding these 2 individuals indicated that the strength of the foraging response showed a highly significant depth effect $\left(F_{1,37}=7.81, \mathrm{p}<0.01\right)$ but no significant species effect $\left(F_{1,37}=1.08, \mathrm{p}=0.3\right)$ or species $\times$ depth interaction $\left(F_{1,37}=2.60, \mathrm{p}=0.1\right)$.

We repeated these analyses using foraging illumination as the response variable. Responses for both species were very similar with significant bird effects, TML.I ${ }^{2}$ effects and interactions (blue-eyed shags: $F_{1,14}=$ $115.29, \mathrm{p}<0.001, F_{1,14}=11.45, \mathrm{p}<0.01, F_{1,14}=20.2, \mathrm{p}<$ 0.001 , respectively; European shags: $F_{1,20}=27.09, \mathrm{p}<$ $0.001, F_{1,20}=28.94, \mathrm{p}<0.001, F_{1,20}=19.13, \mathrm{p}<0.001$, respectively). In both cases the regression coefficient 


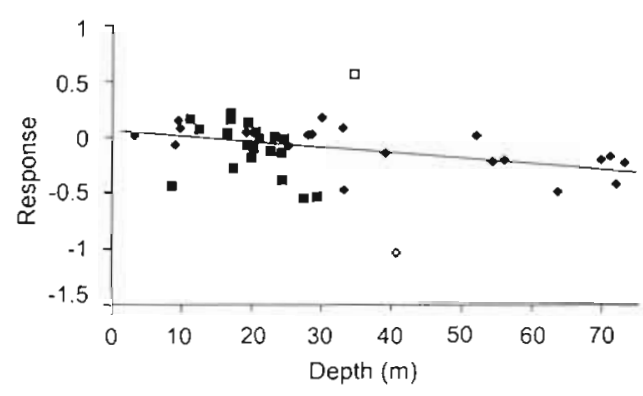

Fig. 4. Relationship between the diel depth response shown by individual blue-eyed shags ( $\bullet$, and European shags ( and their mean foraging depth. Fitted line was estimated after excluding the 2 outliers (blue-eyed shag: $\diamond$. European shag: D)

for the time-of-day effect indicated that foraging illumination was higher around midday compared with conditions earlier or later in the day. Hence, on average, the increase in dive depth was consistently less than the increase in light penetration through the water column.

\section{DISCUSSION}

The data presented here are the first direct measurements of foraging illumination for any phalacrocoracid. They indicate that the minimum values for blue-eyed and European shags were -1.30 and $0.22 \log _{10} \mathrm{~lx}$ respectively, figures which are equivalent to the illuminance at ground level produced by a half moon under clear skies and a full moon under clear skies respectively (Fig. 2.1 in Martin 1990). Compared with other diving birds, minimum values for shags are similar to those of little penguins Eudyptula minor $\left(-0.22 \log _{10} 1 x\right.$; Cannell \& Cullen 1998) but are much higher than those of king penguins Aptenodytes patagonicus (ca-10.0 $\log _{10}$ lx; Martin 1999).

Our results are in accordance with previous studies which indicate that cormorants and shags are diurnal feeders (Johnsgard 1993). However, as far as we are aware, they are the first to demonstrate a consistent periodicity in depth utilisation with individuals diving deeper around midday compared to earlier or later in the day. This is consistent with the hypothesis that foraging depth varies in relation to the diel light cycle and supports the specific prediction that dive depths should be maximised when the light penetration through the water column is greatest. However the strength of the response shown by blue-eyed shags and European shags was much less extreme than that found in studies of penguins (Wilson et al. 1993, Kirkwood \& Robertson 1997, Peters et al. 1998,
Pütz et al. 1998). We conclude that this stems mainly from differences in feeding ecology between the 2 groups. Penguins are predominantly pelagic feeders, and depth responses are therefore likely to be accentuated by the diel vertical migrations of their prey species. In contrast, blue-eyed shags and European shags are believed to be predominantly benthic feeders. We also found evidence of individual differences in the strength of the depth response which were consistent with the hypothesis that illumination influences dive depth. Thus the strongest responses were shown by the deepest diving birds, i.e. those individuals in which foraging efficiency was most likely to be limited by the visual threshold of the species.

Although there was evidence of significant changes in shag diving behaviour in response to the diel light cycle, neither species fully exploited the potential of this effect. Hence, on average, the strength of the depth response was less than the increase in light penetration through the water, with the net result that the illumination levels experienced by an individual foraging around midday were consistently higher than those it experienced earlier or later in the day. Presumably, this behavioural choice reflects other constraints such as the distribution of prey, the distribution of bottom types appropriate for foraging, or the costs of diving. We did not measure prey capture rates and therefore the extent of any diel variation in foraging efficiency in shags remains unknown. Evidence from other Phalacrocorax species has suggested that they may be partially tactile predators (Cooper 1984, Voslamber et al. 1995), which could potentially buffer them against changes in illumination. Illumination merits further consideration in investigations into how benthic feeders detect their prey and the factors which affect their foraging efficiency.

Acknowledgements. We thank members of the British Antarctic Survey Bird Island base for assistance in the field and Scottish Natural Heritage for granting us permission to work on the Isle of May National Nature Reserve. We also wish to thank C. Hall for assistance in the calibration of the TDRs and G. Martin and D. Gremillet for comments on an earlier draft of the manuscript. S.W. received a British Ecological Society Travel Grant to cover expenses to and from the Falkland Islands.

\section{LITERATURE CITED}

Boyd IL, McCafferty DJ, Walker TR (1997) Variation in foraging effort by lactating Antarctic fur seals: response to simulated increased for aging costs. Behav Ecol Sociobiol 40:135-144

Campbell B, Lack E (1985) A dictionary of birds. T \& AD Poyser Ltd, Calton, UK

Cannell BL, Cullen JM (1998) The foraging behaviour of little penguins Eudyptula minor at different light levels. Ibis 140:467-471 
Cooper J (1984) Biology of the bank cormorant, Part 3: Foraging behaviour. Ostrich 56:86-95

Croxall JP, Naito Y, Kato A, Rothery P, Briggs DR (1991) Diving performance in the Antarctic blue-eyed shag Phalacrocorax atriceps. J Zool Lond 225:177-199

Culik BM, Wilson RP (1991) Swimming energetics and performance of instrumented Adelie penguins (Pygoscelis adeliae). J Exp Biol 158:355-368

Johnsgard PA (1993) Cormorants, darters and pelicans of the world. Smithsonian Institution Press, Washington, DC

Kirkwood R, Robertson G (1997) The foraging ecology of female emperor penguins in winter. Ecol Monogr 62:143-163

Marchant S, Higgins PH (1990) Handbook of Australian, New Zealand and Antarctic birds. Oxford University Press, Melbourne

Martin GR (1990) Birds by night. T\& AD Poyser Ltd, London

Martin GR (1999) Eye structure and foraging in king penguins Aptenodytes patagonicus. Ibis 141:444-450

Minitab Inc. (1996) Minitab reference manual; Release 11.2. Minitab, State College, PA

Nevitt GA, Veit RR, Kareiva P (1995) Dimethyl sulphide as a foraging cue for Antarctic Procellariiform seabirds. Nature 376:680-682

Peters G, Wilson RP, Scolaro JA, Laurenti S, Upton J, Galleli H (1998) The diving behaviour of Magellanic penguins at Punta Norte, Peninsula Valdes, Argentina. Colon Waterbirds $21: 1-10$

Pütz K, Wilson RP, Charrassin JB, Raclot T, Lagie J, Le Maho

Editorial responsibility: Otto Kinne (Editor),

Oldendorf/Luhe, Germany
Y, Kierspel MAM, Culik BM, Adelung D (1998) Foraging strategy of king penguins (Aptenodytes patagonicus) during summer at the Crozet Islands. Ecology 79 : 1905-1921

Schmid D, Gremillet DJH, Culik BM (1995) Energetics of underwater swimming in the great cormorant (Phalacrocorax carbo sinensis]. Mar Biol 123:875-881

Voslamber B, Platteeuw M, Eerden MR (1995) Solitary foraging in sand pits by breeding cormorants Phalacrocorax carbo sinensis: does specialised knowledge about fishing sites and fish behaviour pay off? Ardea 83:213-222

Wanless S, Burger AE. Harris MP (1991) Diving depths of shags Phalacrocorax aristotelis breeding on the Isle of May. Ibis 133:37-42

Wanless S, Harris MP, Morris JA (1992) Diving behaviour and diet of the blue-eyed shag at South Georgia. Polar Biol 12: $713-719$

Wanless S, Harris MP, Russell A (1993a) Factors influencing food-load sizes brought in by shags Phalacrocorax aristotelis during chick rearing. Ibis 135:19-24

Wanless S, Corfield T, Harris MP, Buckland ST, Morris JA (1993b) Diving behaviour of the shag Phalacrocorax aristotelis (Aves: Pelecaniformes) in relation to water depth and prey size. J Zool Lond 231:11-25

Wilson RP, Puetz K, Bost CA, Culik BM, Bannasch R, Reins T, Adelung $\mathrm{D}$ (1993) Diel dive depth in penguins in relation to diel vertical migration of prey: whose dinner by candlelight? Mar Ecol Prog Ser 94:101-104

Submitted: February 15, 1999; Accepted: June 9, 1999 Proofs received from author(s): October 14, 1999 